\title{
DESAFIOS DA RELAÇÃO MUSEU-ESCOLA
}

\section{Educação em museus, além de complementar o currículo formal, é exercício de afetividade e preservação da memória e do patrimônio cultural}

As exposições museológicas são discursos criados com intenção de comunicar idéias, conceitos e informações ao público visitante, tendo como veículo específico os objetos. A ação educativa em museus visa ampliar as possibilidades de aproveitamento pedagógico dos acervos, para que o visitante acentue seu espírito crítico em relação à sua realidade e daqueles que estão à sua volta.

Discutiremos aqui alguns conceitos relacionados à educação em museus de ciências e os desafios existentes na relação entre museu e escola, destacando o papel do educador de museus e do professor nesta relação. Proporemos também a Educação Patrimonial como a metodologia mais apropriada para a ação educativa em museus.

Museu é uma instituição permanente, sem fins lucrativos, que adquire, preserva, documenta, pesquisa e comunica para educação e lazer. Há diversas maneiras de agrupar os museus. Por exemplo: a) esfera responsável - público, privado; federal, estadual, municipal, universitário; b) tipo de acervo - antropologia, arte contemporânea, arte sacra, biológico, histórico; c) áreas de

\section{A AUTORA}

Adriana Mortara Almeida

Educadora do Museu de Arqueologia e Etnologia da USP. E-mail: mortara@usp.br pesquisa - antropologia, arte, arqueologia, herpetologia, saúde pública. A partir dos dois últimos critérios podemos definir dois grandes conjuntos: museus de arte e museus de ciência. Neste artigo trataremos da educação em museus de ciências.

\section{A RELAÇÃO MUSEU-ESCOLA}

A partir do final do século XIX a missão educativa dos museus foi se ampliando, tornando-se, por vezes, sua razão de ser. $\mathrm{Na}$ Europa, a criação de departamentos de educação nos museus viabilizaria a política de dar acesso a todas as formas de conhecimento para a população, forjando o cidadão. Essa idéia vem no sentido de reforçar o nacionalismo e o espírito democrático, tanto em países centrais (colonizadores) quanto nos periféricos (colonizados). A educação é um meio de formar trabalhadores, eleitores que se identifiquem com a trajetória de sua pátria e atuem no sentido de preservar sua integridade.

Em 1880, o Louvre (Paris) criou seu serviço educativo permanente. Entre 1914 e 1918 o Victoria \& Albert Museum (Londres) organizou um programa de exercícios artesanais relacionados com as peças do seu acervo para estudantes. A partir de 1920 foram realizadas diversas experiências pedagógicas nos EUA que iriam firmar definitivamente a função educativa como fundamental para os museus. 
No Brasil, a ação educativa em museus recebeu influências das idéias do escolanovismo, proposta técnico-pedagógica liderada por Fernando de Azevedo, disseminada no Brasil a partir de 1920 , que ao mesmo tempo em que determinaram a modernização dos museus, definiram-lhe o perfil de agente empenhado no complemento do ensino escolar. Mais tarde são as propostas da educação permanente, disseminadas pela UNESCO a partir da década de 60 , que vão tratar dos museus propondo que estes desenvolvam ações complementares ao ensino formal.

A idéia da visita ao museu como complemento e/ou ilustração das questões tratadas em sala de aula permanece até o presente. Contrapondo-se a esta idéia, Margaret Lopes defende o fim da escolarização dos museus, ou seja, o fim da "incorporação pelos museus das finalidades e métodos do ensino escolar...". Para ela, os problemas enfrentados pelos museus decorrem do fato de serem instituições de saber oficializado, que como a escola se empenham em manter a ordem social vigente. Lopes propõe que o museu colabore com "o processo de construção do conhecimento em nossa realidade" e seja um espaço "de veiculação, produção e divulgação de conhecimentos, onde a convivência com o objeto - realidade natural e cultural - aponte para outros referenciais para desvendar o mundo"'.

Consideramos que os museus têm potencial para provocar uma experiência de aprendizagem que vai além da simples complementaridade do ensino escolar e que ocorre por meio de estratégias e métodos diferentes daqueles utilizados na escola.
Gostaríamos de salientar que aqui estaremos discutindo a ação educativa em museus para o público escolar; porém é importante lembrar que a ação educativa em museus também visa a outros públicos, como a terceira idade, funcionários e trabalhadores da região, grupos étnicos, entre outros.

\section{O que se pode aprender em um museu?}

Partindo da conjuntura em que as escolas procuram e visitam com frequiência os museus, é preciso entender que estes têm potencial de ultrapassar a complementaridade da escola. Ou seja, os museus proporcionam a experiência com objetos que, em si, podem gerar motivação, curiosidade e questionamento da parte do estudante.

Uma visita ao museu pode proporcionar aprendizagem tanto de elementos cognitivos como afetivos. Consideramos de forma separada estes ganhos para efeito explicativo, pois sabemos que não existe fronteira entre os aspectos cognitivos e afetivos da aprendizagem e um dificilmente ocorrerá sem o outro.

Os ganhos afetivos são aqueles que mais enriquecem a educação em museus e parecem ser os mais possíveis de se realizar comparando-se com o ensino escolar. A motivação para conhecer mais sobre temas tratados e o crescimento pessoal são exemplos de ganhos afetivos. Deixemos claro que o afetivo não é simplesmente gostar, mas também ter esse sentimento voltado para os temas tratados e objetivos propostos para a atividade programada. “... a verdadeira força da experiência no museu não se baseia na eficácia em transmitir grandes quantidades de conteúdo, mas na capacidade de gerar entusiasmo $e$ interesse na aprendizagem da ciência" ${ }^{2}$.

1. LOPES, M.M. A favor da desescolarização dos museus. Educação e Sociedade. São Bernardo do Campo, Instituto Metodista de Ensino Superior, n.40, 1991. p.443-455.

2. BORUN, M. et al. Planets and pulleys: studies of class visits to science museums. Philadelphia, Flanklin Institute, 1983. 
Essa foi a conclusão de um cuidadoso estudo realizado sobre a aprendizagem de conceitos físicos (movimento e astronomia) em dois museus de ciência norte-americanos. Ele indicou que a visita ao museu produz aprendizagem (cognitiva), porém tanto quanto uma aula do mesmo assunto. A diferença está no ganho afetivo, pois a visita à exposição gerou maior interesse dos alunos em aprender mais e foi considerada mais divertida por eles ${ }^{3}$.

\section{EDUCADORES DE MUSEUS E PROFESSORES: DESAFIOS DA INTEGRAÇÃO}

Para percebermos os ganhos (sejam afetivos e/ou cognitivos) de uma visita de escolares ao museu precisamos conhecer como se dá esse processo na prática. Quando nos deparamos com a realidade da visita escolar ao museu, começamos a visualizar várias dificuldades para a realização deste processo educativo. Citaremos a seguir três pesquisas, feitas em museus brasileiros, que evidenciaram a distância entre aquilo que o professor e o educador de museu propõem e o que ocorre objetivamente no desenrolar das visitas.

\section{Museu de Astronomia e Ciências afins: Ciências Exatas}

Cazelli ${ }^{4}$ estuda as programações do MAST, Museu de Astronomia e Ciências afins, voltadas para público escolar (primeiro grau), como o Parque das Ciências (1985-89), e percebe que nem sempre aquilo que a instituição propõe ocorre na práti- ca, muitas vezes porque as expectativas dos alunos e dos professores são diferentes das propostas pela equipe do museu. Os brinquedos montados ao ar livre, que possibilitariam a percepção de leis naturais vividas fisicamente, perderam-se na extrema descontração dos alunos e/ou no rigor dos professores. Os monitores, que só deveriam intervir quando solicitados pelos alunos, foram transformados em demonstradores/operadores de brinquedos, fazendo explicações sistemáticas sobre seu funcionamento e princípios físicos.

Depois de realizar avaliações com professores e algumas atividades externas ao MAST, elaborou-se um novo projeto museológico (1990) no qual se incorporava o acervo histórico à exposição. Propunha-se o atendimento ao público, especialmente escolar; observação do céu e eventos astronômicos; laboratórios didáticos de ciência; projeto brincando com a ciência, cursos e seminários.

Para a equipe do MAST era fundamental a preparação da visita em conjunto com o professor. Foi estabelecido $\mathrm{o}$ atendimento a professores, quando eram mostrados vídeos, realizadas discussões e visita a laboratório, orientação para preparação dos alunos, além de definição dos objetivos e roteiros das visitas. Cazelli verificou que poucos professores utilizavam o material cedido pelo MAST para preparar seus alunos.

Durante a visita, o professor geralmente ficava passivo (observando a atuação de monitores) e não buscava estabelecer relações dos conteúdos vistos no MAST com aqueles trabalhados em sala de aula. 
Nesse caso percebeu-se que, mesmo quando o professor afirma procurar o museu para desenvolver temas trabalhados em sala de aula, e passa por uma orientação prévia, ele não aproveita o ambiente do museu para estabelecer tais relações com seus alunos.

\section{Museu do Folclore Édison Carneiro: Ciências Humanas}

Beatriz Freire discute esse problema da dificuldade de diálogo entre educadores de museus e professores. Ela observou a ação educativa no Museu do Folclore Édison Carneiro (MFEC - RJ) que, entre 1982 e 1986, deslocou o alvo de suas atividades do aluno para o professor. Considerando o professor o agente multiplicador, a equipe do MFEC passou a fazer a visita guiada para o professor como preparação prévia. Segundo a responsável pelo setor, em 1991 “....a prática (visita guiada) mostrou-se inadequada, pois multiplicava-se a demanda de professores que queriam 'ser guiados', sem que se realizasse o objetivo maior da orientação: o de preparar o professor para uma atuação ativa, junto a seus alunos, na ocasião da visita. (....) parecia.... que os professores simplesmente imitavam a visita guiada, reproduzindo-a com seus alunos, até com as mesmas características de linguagem do técnico que o havia orientado. Não havia multiplicação de informações na qualidade que os técnicos consideravam desejável e possível"s.

Diante desses resultados a equipe do MFEC passou a orientar os professores (antes da visita), através de material escrito (guia do museu, bibliografia e folder para crianças) e disponibilidade para preparar em conjunto a visita. O professor, convidado a visitar sozinho a exposição e depois discutir dúvidas com os educadores do MFEC, deveria preparar a visita de seus alunos. Freire observou (de maio a agosto de 1991) que nenhum dos professores participantes da orientação prévia consultou a bibliografia sugerida na Biblioteca do museu, que muitos nem chegaram a levar seus alunos e que apenas um preparou um roteiro para seus alunos. A preparação dos alunos dada pelos professores era genérica e disciplinadora (como se comportar no museu). Apesar de os professores afirmarem utilizar o MFEC como complementação e enriquecimento dos temas trabalhados em sala de aula, "em nenhuma das visitas observadas houve menção aos conteúdos estudados na escola, embora nas entrevistas os professores tenham ressaltado essa ligação" . $^{\circ}$

Para Freire os educadores de museus ainda não dialogam com os professores. Para tanto seria preciso que o museu mostrasse claramente sua proposta de ação educativa: o que é o museu, como se forma o acervo, que tipo de parceria propõe à escola, entre outras coisas.

\section{Museu do Instituto Butantã: Ciências Biológicas}

Para os professores das escolas participantes da nossa pesquisa ${ }^{7}$, a visita ao Museu do Instituto Butantã (MIB) seria uma complementação do que foi visto em sala de aula ou um incentivo ao que seria trabalhado, ou apenas oportunidade de enriquecimento cultural e preenchimento de tempo e condição disponível.

5. FREIRE, Beatriz M. O encontro museu/escola: o que se diz e o que se faz. Rio de Janeiro, PUC-RJ, 1992. p.50-51. (Dissertação de Mestrado).

7. ALMEIDA, A. M. A relação do público com o Museu do Instituto Butantã: análise da exposição "Na natureza não existem vilões". São Paulo, ECA-USP, 1995. (Dissertação de Mestrado). 
Na prática, os professores não prepararam seus alunos para a visita ou apenas trabalharam alguns aspectos da vida dos animais expostos no MIB, sem se preocupar com as mensagens propostas pela exposição.

Durante a visita, os professores tiveram atitude passiva, deixando os alunos livres no passeio. Os alunos se dispersaram e apenas alguns acompanhavam os professores que faziam comentários e respondiam às dúvidas dos alunos.

\section{O PAPEL DO EDUCADOR DE MUSEUS}

A partir dos problemas apresentados na relação entre professores e museus, gostaríamos de colocar qual seria o papel do educador de museu nessa relação.

A educação em museus visa à preservação do patrimônio cultural e natural, através da participação crítica de toda a população. A ação educativa é parte integrante dos processos de comunicação museológica e deve ser coerente com o discurso expositivo, com as publicações e outros meios de divulgação do museu.

$O$ educador de museu pode utilizar diversas estratégias baseadas em diferentes linhas pedagógicas. Várias linhas pedagógicas foram desenvolvidas para o universo escolar, como a construtivista, piagetiana e montessoriana, entre outras. Não nos deteremos nessas linhas pedagógicas pois selecionamos uma proposta educacional baseada na cultura material: a educação patrimonial (heritage education). Consideramos a metodologia da Educação Patrimonial a mais apropriada para a ação educativa em museus por levar em conta os ganhos cognitivos e afetivos da aprendizagem e por partir da especificidade do museu - a cultura material.

\section{Estratégias e métodos da ação educativa em museus: educação patrimonial}

Alguns museus brasileiros vêm utilizando a metodologia da educação patrimonial em sua ação educativa há mais de dez anos. Essa metodologia, inicialmente aplicada pelo Museu Imperial de Petrópolis, foi sendo adaptada por diversos museus e instituições, entre eles o Museu de Arqueologia e Etnologia da USP (onde atuamos na área educativa).

A Educação Patrimonial é definida como o "ensino centrado nos bens culturais, com metodologia que toma estes bens como ponto de partida para desenvolver a tarefa pedagógica; que considera os bens culturais como fonte primária de ensino"

A Educação Patrimonial objetiva colocar o museu como "1) parte da vida comunitária; 2) local onde se preserva a memória cultural e 3) local onde se educa permanentemente pela fonte de imagens, idéias e testemunhos da capacidade criadora do homem em seu processo evolutivo..." .

A proposta de Educação Patrimonial prevê a percepção/observação, motivação, memória e emoção. Sem esses elementos fica difícil o envolvimento afetivo e o interesse do visitante/usuário, necessários para que a aprendizagem ocorra. A observação pode ser exercitada através de desafios e jogos,

8. GRUNBERG, E. Educação Patrimonial - Utilização dos bens culturais como recursos educacionais. (Apresentado no Encontro de Museus do Mercosul), São Miguel, RS, 1995.

9. ALENCAR, V. Museu-Educação: se faz caminho ao andar... Rio de Janeiro, Faculdade de Educação da PUC-RJ, 1987. p.31. (Dissertação de Mestrado). 
aguçando principalmente a visão, mas quando possível também os outros sentidos. A motivação pode ser dada pelo estímulo à imaginação, no caso de crianças, e por outros estímulos para visitantes mais velhos. A memória é fundamental para que se registre a experiência vivida e se estabeleçam relações com experiências do passado. A emoção permite o envolvimento do educando, principalmente no caso das crianças, criando vínculos afetivos ao processo de aprendizagem. "O nível de percepção e de motivação será tanto maior quanto for $\mathrm{o}$ apelo à sensibilidade da criança $\mathrm{e}$ quanto maior for o grau de seu envolvimento afetivo" $"$.

Metodologicamente, a Educação Patrimonial propõe três etapas: identificação do bem cultural (observação e análise); registro do bem cultural (atividades de registro da identificação) e valorização e resgate (interpretação e comunicação do observado e registrado).

A etapa da identificação pode ser feita por exercícios de comparação, memória, questionamento, utilizando e desenvolvendo os sentidos através da observação e análise de materiais, dimensões, formas, elementos, cores, texturas, organização, usos, funções, valores, relações, espaços, movimentos etc.

Na segunda etapa, o registro, são buscadas todas as informações materiais e simbólicas, históricas e culturais a respeito do objeto de estudo, através de desenhos, fotografias, pesquisa de campo com pessoas (entrevistas) ou em documentos (arquivos e bibliotecas, jornais etc).

$\mathrm{Na}$ terceira etapa, valorização e resgate, "é a culminância da experiência viven- ciada. Neste momento se faz a interpretação e comunicação de todo o percebido e registrado. É nessa etapa que se manifesta a capacidade criativa e se retorna o conhecimento adquirido com um julgamento de valor" ". A concretização dessa etapa pode se dar por meio de exposições, dramatizações, elaboração de textos, livros, poesias, jornais e atividades de recreação e lazer. $\mathrm{O}$ objetivo final desse processo é o desenvolvimento do espírito crítico do participante, essencial para a constituição do cidadão ${ }^{12}$.

\section{CONSIDERAÇÕES FINAIS}

A Educação Patrimonial não resolveu todos os problemas da relação entre museus e escolas. Através de atividades propostas previamente para os professores, nas quais eles e seus alunos exercitam sua percepção, e do esclarecimento das etapas e objetivos da ação educativa no museu, estamos caminhando para uma maior compreensão de nosso trabalho por parte dos professores. Essa maior compreensão resulta, por parte dos alunos, numa visita mais produtiva.

As relações entre instituições de ensino formal, como a escola, e de ensino nãoformal, como os museus, podem ser muito profícuas, caso seus profissionais de educação (professores e educadores de museus) estabeleçam canais de comunicação para troca de programas de ação educativa.

Os educadores dos museus precisam criar formas de orientar os professores para 
que eles possam aproveitar ao máximo o potencial pedagógico dos museus. O ideal seria ter programas para os diferentes tipos de grupos de escolares, ou seja, para aqueles que estão estudando temáticas apresentadas no museu, para aqueles que estão de passagem, para aqueles que vão iniciar o estudo de temas apresentados na exposição e para aqueles que vêm fazer uma pesquisa solicitada pelo professor. Para isso seriam necessários mais funcionários, espaço e verbas para material.

Entretanto, devemos estar atentos para não valorizarmos demais os currículos escolares e os procedimentos da escola, para não escolarizarmos os museus.

Através da ação educativa para escolares, o museu pode cumprir a sua função de comunicação para "fins de educação e

Resumo: $\mathrm{O}$ artigo discute a relaçāo museu/ escola e as questōes decorrentes do grau de aproveitamento das informaçōes do acervo pelos professores e alunos visitantes. Relata experiências de educadores de museus que desenvolveram projetos de integraçăo para visitantes de escolas. Propõe a metodologia da Educação Patrimonial como alternativa mais efetiva para a ação educativa em museus.

Palavras-chave: Museu, escola, ação educativa, Educação Patrimonial lazer", criar uma relação de simpatia (afetiva) entre o público e o museu, além de levar esses visitantes a estabelecer uma postura de reconhecimento e preservação do patrimônio. Acreditamos que a metodologia mais apropriada para tal empreendimento seja aquela proposta pela Educação Patrimonial, pois proporciona ao educando uma experiência que pode levar à aprendizagem, com ganhos cognitivos e afetivos, aproveitando a especificidade do museu.

\section{Agradecimentos}

Gostaria de agradecer as sugestões de Maria Helena Pires Martins, Marilúcia Bottallo e Cláudio Aguiar Almeida.

Abstract: The article discusses the museum/school relationship and the questions resulting problems insofar as the actual usage of the information extant in the collection by visiting teachers and students. It reports on the experiences of museum educators who developed integration projects for school visitors. It proposes an Asset Patrimonial Education methodology as a more effective alternative for educational action in museums.

Keywords: Museum, school, educational action, Asset Patrimonial Education 